\title{
Utility of a bespoke 3-dimensional printed model in complex transposition
}

Juan R. Contreras, MD, ${ }^{a}$ Olivier Villemain, $\mathrm{MD}, \mathrm{PhD},{ }^{\mathrm{b}}$ Davide Marini, $\mathrm{MD}, \mathrm{PhD},{ }^{\mathrm{b}}$

Andreea Dragulescu, MD, PhD, ${ }^{b}$ Shi-Joon Yoo, MD, PhD, ${ }^{c}$ and David J. Barron, MD, ${ }^{\mathrm{a}}$ Toronto, Ontario, Canada

From the ${ }^{\mathrm{a}}$ Division of Cardiovascular Surgery, Department of Surgery, ${ }^{\mathrm{b}}$ Division of Cardiology, Department of Pediatrics, and ${ }^{c}$ Division of Cardiology, Department of Diagnostic Imaging, The Hospital for Sick Children, University of Toronto, Toronto, Ontario, Canada.

Disclosures: The authors reported no conflicts of interest.

The Journal policy requires editors and reviewers to disclose conflicts of interest and to decline handling or reviewing manuscripts for which they may have a conflict of interest. The editors and reviewers of this article have no conflicts of interest.

Received for publication Jan 12, 2021; accepted for publication Jan 13, 2021; available ahead of print Jan 19 , 2021.

Address for reprints: David J. Barron, MD, Division of Cardiovascular Surgery, Department of Surgery, The Hospital for Sick Children (SickKids), 555 University Ave, Room 1525-Hill Wing, Toronto, Ontario M5G 1X8 Canada (E-mail: david.barron@sickkids.ca).

JTCVS Techniques 2021;7:199-202

2666-2507

Copyright (C) 2021 The Authors. Published by Elsevier Inc. on behalf of The American Association for Thoracic Surgery. This is an open access article under the CC BY-NC-ND license (http://creativecommons.org/licenses/bync-nd/4.0/).

https://doi.org/10.1016/j.xjtc.2021.01.019

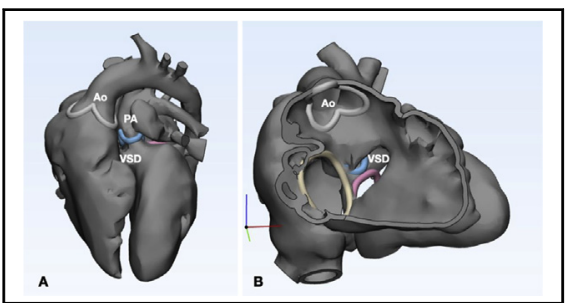

Three-dimensional printed model showing a complex transposition of the great arteries.

\section{CENTRAL MESSAGE}

Echocardiography, MRI, and 3D-

printed models provide multi-

modal information to guide de-

cision making in complex

transposition. Damus-Rastelli

procedure is a valuable surgical

option in this setting.

See Commentaries on pages 203, 204, and 206.
Transposition of the great arteries (TGA), ventricular septal defect (VSD), and left ventricular outflow tract obstruction (LVOTO) are part of the spectrum of complex TGA. Several surgical techniques have been described, including Rastelli procedure, réparation à l'etage ventriculaire (REV), and the Bex-Nikaidoh procedure. Nevertheless, the optimal surgical repair is still controversial and can depend on the morphology of any individual patient, especially if there are abnormal coronary patterns. ${ }^{1}$ Modern imaging techniques, combining 3-dimensional (3D) printing with bespoke model orientation and annotation, can facilitate decision making. We present a case of successful repair with Damus-Rastelli procedure using echocardiography, magnetic resonance imaging (MRI), and a 3D model in the assessment of a patient with a complex TGA. Consent was obtained from the parents.

\section{CASE REPORT}

A 7-month-old-infant with TGA, VSD, and LVOTO (pulmonary valve stenosis) was brought to us for treatment. Antenatally diagnosed and born at full-term with balanced circulation, running oxygen saturation in the high $80 \mathrm{~s}$. Transthoracic echocardiogram confirmed a large, predominantly inlet perimembranous VSD slightly remote from the aorta. The pulmonary valve (PV) was bicuspid, stenotic, and hypoplastic $(z$ score, -4$)$ with good sized confluent branch pulmonary arteries (PAs) and small patent ductus.

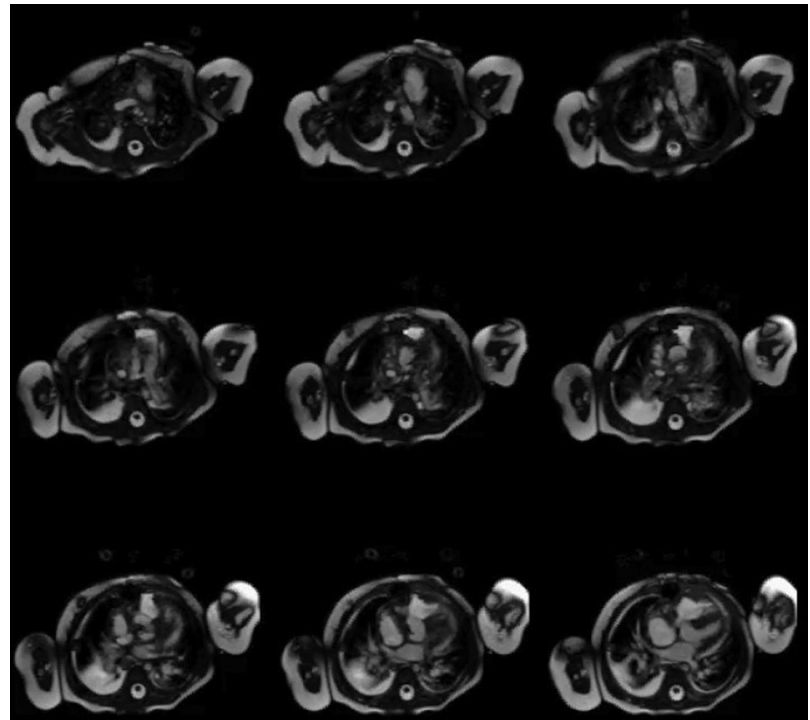

VIDEO 1. Free-breathing axial cine steady-state free precession images illustrating the surgical result. Video available at: https://www.jtcvs.org/ article/S2666-2507(21)00085-7/fulltext. 


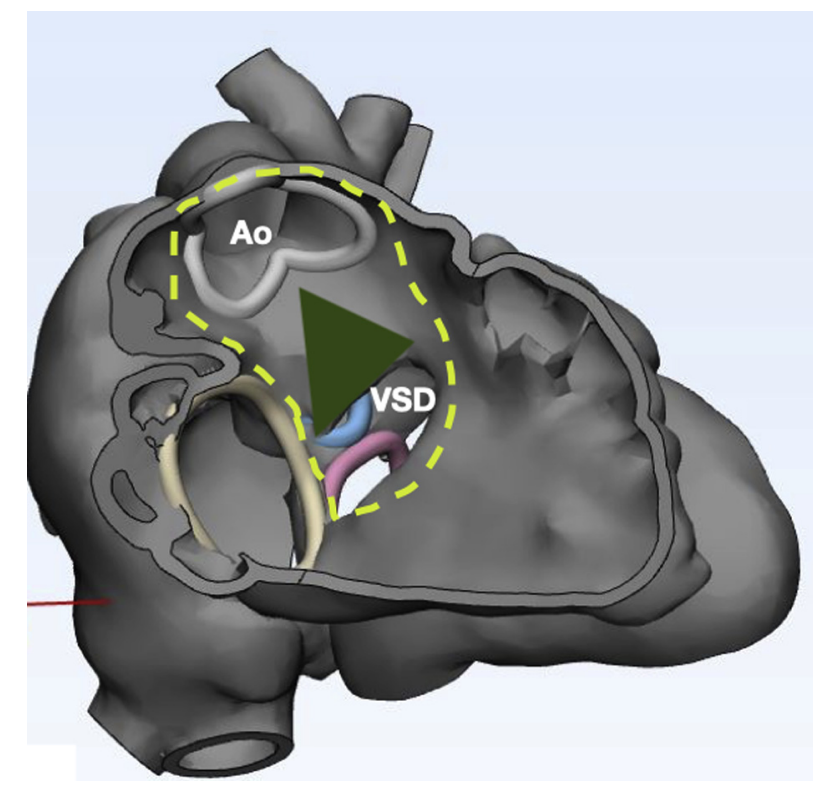

FIGURE 1. Diagram describing the intracardiac repair. The green triangle demonstrated the ventricular septal defect (VSD) enlargement with infundibular resection and the dotted yellow line indicates the intracardiac baffle. Ao, Aorta.
In addition, echocardiography and computed tomography angiography confirmed a single coronary pattern with intramural origin arising posteriorly with the left and right coronary arteries running between the 2 great arteries.

Cardiac MRI and a series of bespoke and annotated 3D models were made to help us consider the options for surgical repair. It was determined that the patient's coronary artery anatomy would preclude Bex-Nikaidoh procedure as an option and that both Damus-Rastelli ${ }^{2}$ procedure and REV would leave a long and angled LVOT of borderline size. The 3D model helped to visualize the extent of the infundibular septum and accurately show the position of the pulmonary annulus such that the steps necessary for VSD enlargement could be appreciated. As a result, we maximized the size of the LVOT while preserving the PV and incorporating the pulmonary root into a DamusRastelli type repair. The MRI alone did not allow the same appreciation that was achieved with the 3D model (Video 1 and Figures 1 and 2).

At age 7 months, the patient underwent a Damus-Rastelli procedure consisting of an LV to aorta intracardiac baffle, VSD enlargement by resection of the infundibular septum,
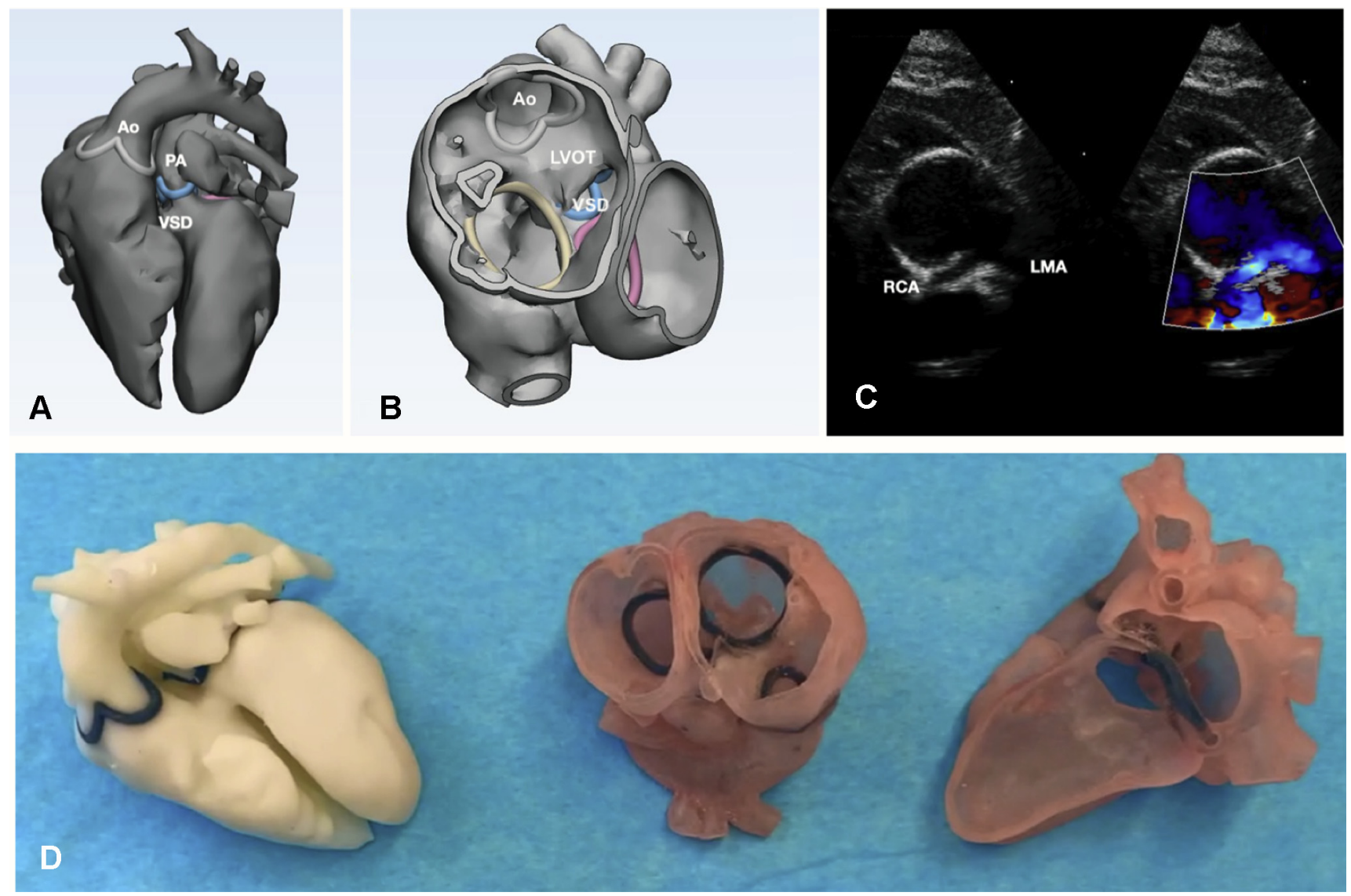

FIGURE 2. Multimodal images showing transposition of the great arteries (TGA), ventricular septal defect (VSD), small pulmonary artery ( $P A$ ) and single coronary artery. A and B, reconstruction in 3 dimensions of the magnetic resonance imaging scan. C, Echocardiogram short axis showing a single coronary artery with intramural and intra-arterial trajectory. D, The 3-dimensional models. Ao, Aorta; LVOT, left ventricular outflow tract; RCA, right coronary artery; LMA, left mainstem coronary artery. 

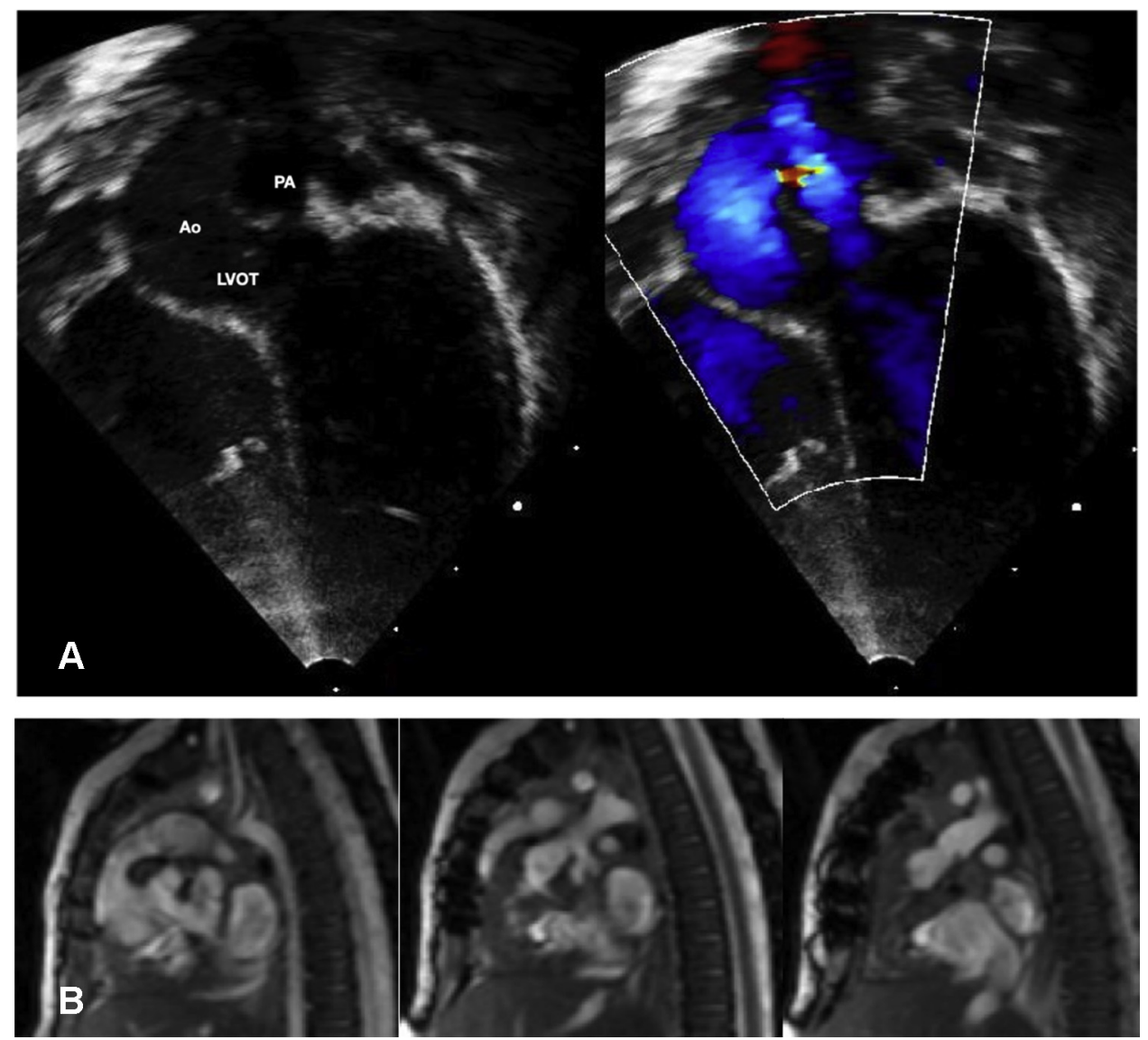

FIGURE 3. A, Postoperative echocardiographic 2-dimensional apical view, showing the intracardiac baffle, unobstructed left ventricular outflow tract, and anastomosis between pulmonary artery and the posterior wall of the aorta (Damus-Rastelli). B, Magnetic resonance imaging single-shot steady-state free precession images in sagittal view showing the right ventricle-pulmonary artery conduit (left panel), the Damus-Rastelli (central panel), and the ascending aorta (right panel). Ao, Aorta; $P A$, pulmonary artery; LVOT, left ventricular outflow tract.
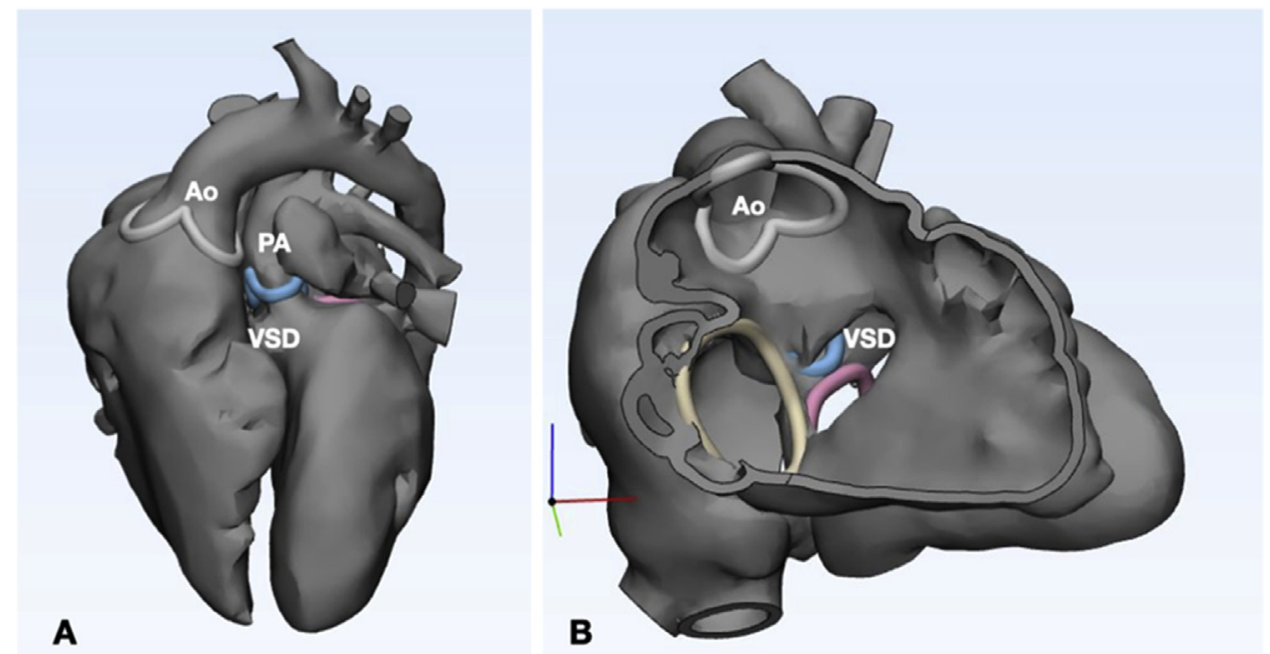

FIGURE 4. Three-dimensional reconstructed image showing complex transposition of the great arteries. A, External view, B, With anterior wall of the right ventricle removed. Ao, Aorta; $P A$, pulmonary artery; $V S D$, ventricular septal defect. 


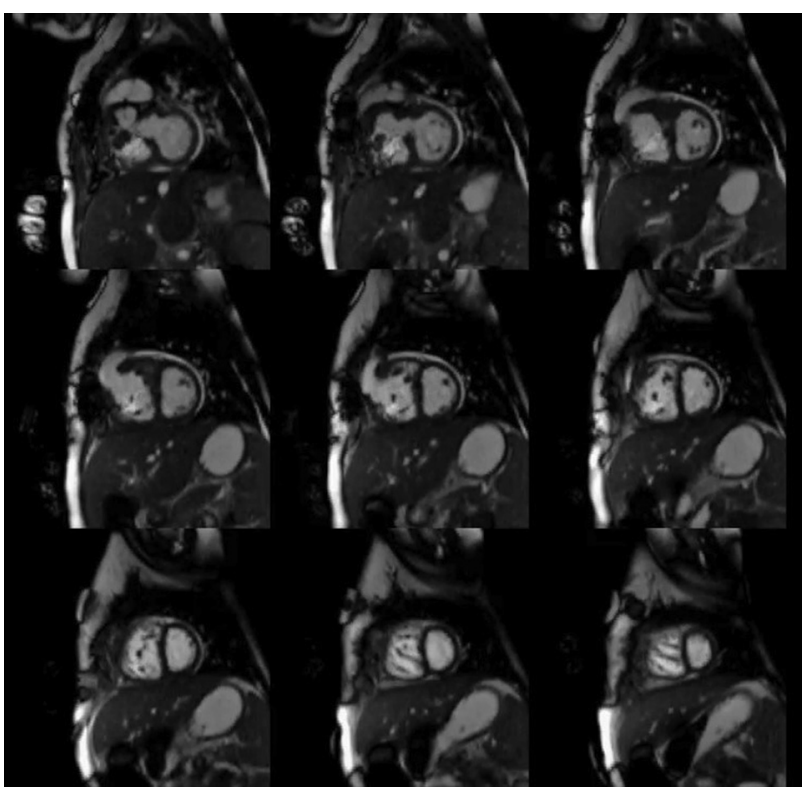

VIDEO 2. Free-breathing steady-state free precession images illustrating the surgical result in short axis view. Video available at: https://www.jtcvs. org/article/S2666-2507(21)00085-7/fulltext.

aorto pulmonary Damus connection, atrial septal defect closure, and right ventricle-PA conduit with a 14-mm Contegra (Medtronic, Minneapolis, Minn) conduit.

Intraoperative transesophageal echocardiogram and epicardial echography showed unobstructed LV to aorta baffle, no pulmonary or aortic regurgitation, that the right ventricle-PA conduit and the PAs were unobstructed, and there was good biventricular function (Figure 3).

The patient was extubated a few hours after surgery in the critical care unit, transferred to the ward the next day, and discharged home on postoperative day 4 . The 15-days and 2-months postoperative follow-ups showed unobstructed LVOT and stable result by echocardiography and MRI.

\section{DISCUSSION}

The decision making is crucial to achieving optimal outcomes in patients with complex anatomy such as TGAVSD-LVOTO. The single coronary pattern in this patient added to the complexity. The Damus-Rastelli procedure was chosen due to the single-origin intramural coronary pattern that would make Bex-Nikaidoh procedure very challenging, the remote VSD necessitating creation of a long LVOT, and the presence of a small but functional PV that could contribute to the LV outflow. Indeed, REV would have been an option, but we believed that it would be better to try to use the small but useful forward flow through the PV.,

Echocardiography, MRI, 3D reconstructions, and annotated 3D-printed models all contributed to defining the

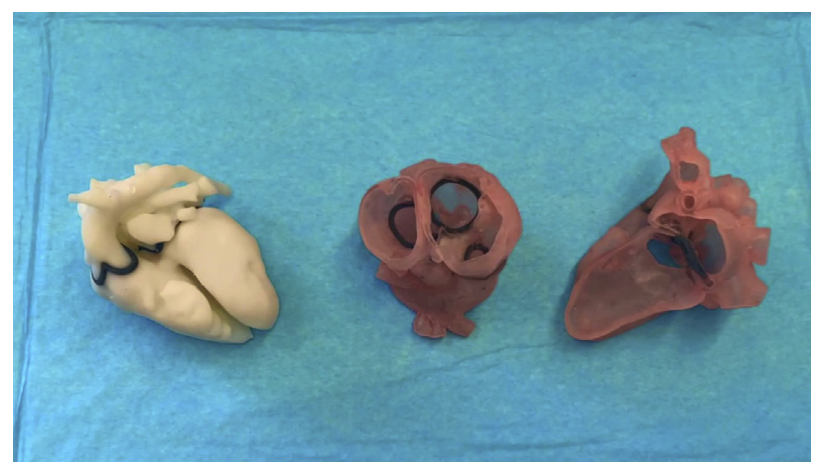

VIDEO 3. Anatomical description based on 3-dimensional printing model. Video available at: https://www.jtcvs.org/article/S2666-2507(21) 00085-7/fulltext.

anatomy and to our decision. In view of the multiple surgical options available for a biventricular strategy, it was crucial to assess each anatomical parameter by multimodal evaluation. Printed models can be generated in specific orientations to highlight the key components of the anatomy, and they can be annotated to emphasize the position of key structures such as the valve annuli (Figure 4 and Videos 1 and 2).

The 3D imaging and models helped us plan the procedure and consider the implications of various surgical approaches, allowing us to exclude some approaches before coming to the most suitable. The rapid advancement in 3D printing technology allows users to now select different orientations and cut away free-wall structures to focus on the area of interest, whereas newer materials make the models easier to handle and translucent to aid 3D conceptualization (see Video 3).

The limitation of these models is that they cannot show the valve leaflets, subvalvular apparatus and their relationship to the VSD, and outflow tracts, for which echocardiography imaging is still essential and has to be incorporated into the decision-making process.

\section{References}

1. Honjo O, Kotani Y, Bharucha T, Mertens L, Caldarone CA, Redington AN, et al. Anatomical factors determining surgical decision-making in patients with transposition of the great arteries with left ventricular outflow tract obstruction. Eur J Cardiothorac Surg. 2013;44:1085-94.

2. Kalfa D, Vergnat M, Baruteau AE, Belli E. Damus anastomosis associated with REV/Rastelli procedure allows to extend indications for anatomical repair in complex transposition of great arteries. Interact Cardiovasc Thorac Surg. 2014;18: 844-6.

3. Ceithaml EL, Puga FJ, Danielson GK, McGoon DC, Ritter DG. Results of the Damus-Stansel-Kaye procedure for transposition of the great arteries and for double-outlet right ventricle with subpulmonary ventricular septal defect. Ann Thorac Surg. 1984;38:433-7.

4. Kumar TKS, Amin N, Sathanandam S, Knott-Craig CJ. Management of coronary artery arising from nonfacing sinus in transposition of great arteries. J Thorac Cardiovasc Surg. 2018;156:e189-90. 